\title{
Die Afrikaanse Bybelvertaling 1983 - enkele aantekeninge
}

\section{JP OBERHOLZER}

Die publikasie van 'n nuwe Afrikaanse Bybelvertaling op 2 Desember 1983 het die seël geplaas op 'n besondere feesjaar, Biblia 1983, waarin die verskyning van die eerste volledige Afrikaanse Bybelvertaling op 24 Augustus 1933 in feestelike herinnering geroep is. Dit was dus terselfdertyd 'n jaar waarin die afskeid van die 1933vertaling en die omgang met 'n nuwe vertaling 'n aanvang geneem het. Sowel die afskeid van die oue as die oorgang na gebruik van die nuwe is 'n proses waarvan die einde nie voorsien kan word nie. Die ondervinding in ander taalgebiede leer trouens dat van baanbrekende vertalings nie afskeid geneem word nie. Die Duitse Luthervertaling, die Nederlandse Statevertaling en die Engelse Authorised Version leef kragtig voort, en van die Afrikaanse 1933-vertaling kan miskien dieselfde verwag word.

Bedoeling van hierdie artikel is om 'n oorsig te gee van die wording van die nuwe, 1983-vertaling, en wel 'n vlugtige, onvolledige oorsig waarin ek slegs uit eie dokumentasie en herinnering put. Toe ek in 1965 benoem is in die Kommissie vir die Hersiening) van die Afrikaanse Bybel, was die hersieningsfase reeds etlike jare aan die gang. In hierdie fase het van die beoogde hersiening weinig gekom, maar die belangrike resultaat was die besef dat nie ' $n$ hersiening nie, maar 'n huwe vertaling die aangewese weg was. Dit was veral prof. $\mathrm{AH}$ van $\mathrm{ZyI}$, sekretaris van die Hersieningskommissie, wat geargumenteer het dat liefs nie geskaaf en gelap moes word aan 'n geëerde en gewaardeerde bestaande vertaling wat in eie tyd en omstandigheid vergelyking met tydgenootlike vertalings ten beste kon deurstaan nie. Deurslaggewend was uiteindelik die besprekings op ' $n$ Vertalingseminaar wat op 1-5 Julie 1968 an die Universiteit van Pretoria plaasgevind het. Gassprekers op dié seminaar was dr. Eugene A Nida van die Amerikaanse Bybegenootskap en kanunnik RWF Wootton van die Britse en Buitelandse Bybelgenootskap. Onder die seminaargangers was naas die lede van die hersieningskommissie ook verteenwoordigers van die drie Afrikaanse Kerke, taalwetenskaplikes op die gebied van Afrikaans, Hebreeus en 
Grieks, personeellede van die Bybelgenootskap van Suid-Afrika en enkele ander gaste. Van Hervormde kant was teenwoordig: proff. ES Mulder en SPJJ van Rensburg, drr JP Oberholzer en CJ Mans, di AJ Nolte en JJ Engelbrecht. Na afloop van die seminaar op Vrydag 5 Julie 1968 het die Kommissie vir die Hersiening van die Afrikaanse Bybelvertaling vergader en die volgende besluit geneem:

"Die vergadering neem kennis van die volgende besluit wat deur die seminaargangers as persverklaring uitgereik is: 'Die vergadering is van oordeel dat, aangesien die bestaande Afrikaanse Bybelvertaling in 1933 deur die Afrikaanse kerke in Suid-Afrika aanvaar is, slegs nege jaar nadat Afrikaans amptelike taal geword het, die tyd nou aangebreek het dat gewerk word aan 'n vernieude vertaling, wat rekening hou met die ) ontwikkeling van Afrikaans in die afgelope tydvak en diet resultate van wetenskaplike ondersoek, so getrou as moontlik aan die grondteks; 'n waardige vertaling wat ons volk aanspreek binne en buite die kerk, in die erediens en huislike gebruik, in ons teenwoordig situasie en tyd.' Vervolgens is besluit dat hierdie besluit deur die Bybelgenootskap aan die verskillende kerke voorgelê sal word ten einde hulle samewerking te verkry vir die vernieude vertaling."

Op dieselfde vergadering is op versoek van ds JTM de Jongh van Arkel, hoofsekretaris van die Bybelgenootskap van Suid-Afrika, besluit om 'n proefvertaling gereed te maak van drie boeke uit die $\mathrm{Ou}$ en drie uit die Nuwe Testament met die oog op die 150-jarige bestaan van die Bybelgenootskap van Suid-Afrika in 1970. (1 Sam prof AH van Zyl; Amos - prof. ES Mulder; Maleagi - dr JP Oberholzer; die Evangelie volgens Johannes - prof EP Groenewald; die briewe aan die Filippense en Kolossense - prof JJ Muller); hierdie proefvertaling is nagesien op ' $n$ byeenkoms van vertalers te Hibberdene aan die Natalse Suidkus op 27 Junie-17 Julie 1969. Publikasie het geskied in 1971. Tereg sê die vertalers in die voorwoord dat hulle dit as 'n proefvertaling beskou waarin daar nog na die gulde weg gesoek word. Die onderskeie vertalings dra die stempel van elke vertaler baie duidelik en talle sake was nog onopgeklaar. In die voorwoord word egter ook die volgende gesê: "Die enigste gemeenskaplike vertalingsbeginsel wat dwarsdeur die hele vertaling van hierdie ses boeke loop, is die strewe van die vertalers om die woord 
in duidelike, verstaanbare en waardige Afrikaans aan te bied." Hierdie strewe sou met verloop van tyd nie verander word nie en sou inderdaad tot in 1983 beklemtoon word as werklik die enigste vertalingsbeginsel ten grondslag van die vertaalwerk.

Die sinodes van die onderskeie kerke het intussen die besluit van die 1968-seminaar as eie besluite aanvaar en hulle onderskeie verteenwoordigers op die nuwe vertalingskommissie benoem. Die nuutsaamgestelde kommissie vir die Afrikaanse Bybelvertaling het bestaan uit proff ES Mulder, JP Oberholzer en ds GMM Pelser namens die Nederduitsch Hervormde Kerk, proff $S$ du Toit en $T$ van der Walt namens die Gereformeerde Kerk (ds J Postma het spoedig daarna bygekom) en proff EP Groenewald, AH van Zyl, FC Fensham, PA Verhoef en FJ Botha namens die Nederduitse Gereformeerde Kerk. Op die eerste vergadering, 2 Februarie 1971 te Pretoria, is prof EP Groenewald verkies tot voorsitter, prof $S$ du Toit tot onder-voorsitter, prof $\mathrm{AH}$ van $\mathrm{Zyl}$ tot sekretaris en ds GMM Pelser tot assistentsekretaris. Hulle sou voortaan as dagbestuur optree. Ter wille van die belangrikheid daarvan laat ek hier volg die eerste paragraaf uit die notule van hierdie vergadering.

"Ds JTM de Jongh van Arkel open met skriflesing uit I Petrus 1 en prof ES Mulder open met gebed.

Ds Van Arkel verwelkom al die lede en vestig die aandag op die belangrike taak wat hier begin. Tog is dit maar net nog ' $n$ skakel in die lang geskiedenis van Bybelvertaling. Dit is ' $n$ werk van ewigheidswaarde. Oor die aard van die vertaling vestig hy die aandag van die vergadering daarop dat die Bybelgenootskap nie 'n "vorm"-vertaling verlang nie, maar wel 'n dinamiese vertaling in hedendaagse Afrikaans ooreenkomstig die besluit wat op 5 Julie 1968 tydens die vertalerseminaar geneem is. Ons moet strewe na 'n verstaanbare vertaling met vermyding van teologies-tegniese, tradisioneel-kerklike begrippe, hoogdrawendheid en letterlikheid. Begrippe soos geregtigheid, goedertierenheid, geregverdig deur die geloof, is in dié verband vermeld. Die lang sinne moet opgebreek word in korter sinne en strewe na eenvoud. Maak soms eksplisiet wat implisiet in die teks is. Die NEB het ook nog gefouteer. Hulle was bang om t.o.v. sekere woorde en aanspreekvorme aanstoot te gee en daarom het hulle selfs nog vorme soos "thee" en "thou" behou, al is dit verouderde woorde wat nie meer ge- 
bruik word nie. Dit blyk tans die vernaamste kritiek teen hulle te wees. Dit was 'n oordeelsfout omdat tradisionalisme nog té 'n groot rol by hulle gespeel het.

As grondteks word gebruik die nuutste Kittel Bybel en die derde druk van die Bybelgenootskap se uitgawe van die Nuwe Testament in Grieks wat identies sal wees aan die 26ste edisie van die Nestlé-Alant-teks.

Die werk moet met spoed gedoen word. Die NT behoort binne drie jaar gereed te wees - die OT sal ietwat langer neem. Dit bring mee dat daar hard gewerk moet word en gereeld vergader moet word. Die kommissie moet poog om nie maar net nog 'n vertaling te maak nie - dit moet werklik 'n nuwe vertaling wees wat ons mense kan aanspreek in die laaste dekades van die twintigste eeu en dalk ook nog in die eerste dekade van die een-en-twintigste."

Hieruit blyk dat ds Van Arkel se aandeel in die gedagte en rigting van'n nuwe vertaling in herinnering behoort te bly. Hy het reeds op 5 Julie 1968 die begeerte van die Bybelgenootskap soos volg geformuleer: "Die Bybelgenootskap van Suid-Afrika voel die noodsaaklikheid vir'n dinamiese nuwe Afrikaanse Bybelvertaling, getrou aan die beste grondteks, waardig vir kanselgebruik en verstaanbaar vir leser en hoorder." Daar was groot entoesiasme by die vertalers op hierdie vergadering, en 'n eerste toewysing van boeke is gemaak vir konsepvertalings. Die gedagte was dat die konsepte, sodra hulle voltooi is, uitgeruil sou word onder die vertalers en dat elke vertaler verantwoordelik sou wees om die kommentaar en kritiek op sy vertaling te verwerk en 'n tweede konsep gereed te maak wat dan behandel sou word op 'n vergadering van die vertalers. Van hierdie metode sou mettertyd afgesien word omdat gevind is dat dit juis in die vertalersvergadering is dat die aandag opgeskerp en uiteindelik goeie formulerings gevind word. Waar in hierdie eerste vergadering nog die gedagte bestaan het dat die Nuwe Testament binne drie en die $\mathrm{Ou}$ Testament binne vyf jaar voltooi sou kon word, sou dit uiteindelik 13 jaar neem voordat die volledige nuwe vertaling gepubliseer sou kon word. Dit sou duidelik word dat so 'n totaal nuwe vertalingsprojek eers ' $n$ lang tyd vereis waarin die vertalers saam met die taaladviseurs kan groei tot 'n gekoördineerde werkspan wat vrugbare werk verrig. Baie tyd sou verlore gaan en baie energie as verspil bewys word voordat die vertaalwerk op koers sou kom. Wat 
die Ou Testament betref, was die karige resultate van die werk in 1971 en 1972 na vyf sittings van die Vetalingskommissie slegs sowat vyftig hoofstukke, ses en twintig van 2 Samuel, sewentien van Eksodus en 'n paar uit die profete. Dit was 'n eerste hersiening, maar die vaardigheid het nog ontbreek sodat al hierdie werk later van vooraf oorgedoen moes word.

Op versoek van die Bybelgenootskap het die Suid-Afrikaanse Akademie vir Wetenskap en Kuns vir proff $W$ Kempen, $H$ Venter en GS Nienaber as taaladviseurs en prof WEG Louw as letterkundige adviseur benoem. Prof Kempen het reeds die vergadering van 7-11 Junie 1971 bygewoon en sou mettertyd 'n volle lid van die Eindredaksie word. Anders as met die 1933-vertalingsprojek het die taaladviseurs nou gereeld sitting geneem op die vertalersbyeenkomste en kon hulle van die begin af 'n lopende bydrae lewer tot die gestalte van die vertaling, ' $n$ metode wat baie beter is en uiteindelik beter resultate afwerp as dié een waarin hulle slegs die konsepte voor hulle kry en op hulle eie deurwerk en kommentarieer. Elke adviseur het na die aard en omstandigheid ' $n$ bydrae gelewer tot die wording van die vertaling, proff Nienaber en Venter hoofsaaklik ten opsigte van die Nuwe Testament, prof WEG Louw sporadies hoofsaaklik ten opsigte van die Psalms, terwyl prof $W$ Kempen feitlik deurgaans teenwoordig was by $\mathrm{Ou}$ - sowel as Nuwe-Testamentiese sittings. As iset in mens na die jare terugkyk, moet dit geboekstaaf word dat sy s to bydrae tot die finale gestalte van die vertaling enorm groot was. ristestin . Danksy sy leiding sou die vertalers mettertyd 'n beter insae kry in di- amio tipe die eise wat deur' $n$ dinamiese vertaling in eietydse Afrikaans gestel word. Daar sou 'n slypingsproses plaasvind met as resultaat dat in later jare daar doeltreffender en vinniger gewerk kon word.

Vanaf 1973 is die werk aan die ander Ou-Testamentiese boeke voorlopig gestaak en is daar toegespits op die Psalms. Wat betref die Ou Testament is die jare 1973 tot 1978 hoofsaaklik in beslag geneem deur die werk aan die Psalms, aanvanklik met die oog op die publikasie van 50 Psalms in die Blye Boodskap wat in 1975 gepubliseer is en daarna met die oog op die publikasie van die Nuwe Testament en Psalms in 1979.

Op die vergadering van 5 Oktober 1973 is ' $n$ Eindredaksie benoem bestaande uit proff EP Groenewald, voorsitter, AH van Zyl, sekretaris, en proff JP Oberholzer, $T$ van der Walt en $W$ Kempen. Hierdie eindredaksie moes die finalisering van manuskripte vir publikasie behartig vir die Ou sowel as die Nuwe Testament. Dit het meege- 
bring dat bv. in 1977 en 1978 die meeste van die sittings aan die werefirmid in Nuwe Testament bestee moes word. Agterna gesien het dit beteken tritime on ent dat die noodsaaklike slypingsproses waarin vertalings- en taalvaardigheid ontwikkel moes word, plaasgevind het aan die Psalms en die Nuwe Testament. 'n Toekomstige vertalingsprojek moet liefs die werk aan die Psalms en die Nuwe Testament tot die laaste toe laat, r sher -1 the staan, sodat dié Bybelgedeeltes waaroor lesers en ook vertalers die hom tees sensitiefste is, aan die orde kom wanneer die vertaalspan die hoogtepunt van sy vaardigheid bereik het. Soos dit ontwikkel het, het die Nuwe Testament en Psalms nege jaar geneem om te voltooi, terwyl die res van die Ou Testament slegs vier jaar geneem het.

Prof ES Mulder is oorlede op 11 Mei 1974 en prof S du Toit het in Januarie 1975 weens swak gesondheid bedank. Hulle plekke is onderskeidelik deur proff WC van Wyk en JL Helberg ingeneem. Nadat prof $\mathrm{T}$ van der Walt rektor geword het van die $\mathrm{PU}$ vir $\mathrm{CHO}$, is sy plek in die eindredaksie geneem deur dr J Postma.

Die Blye Boodskap het bestaan uit die vier Evangelies, Handelinge en vyftig Psalms. Dit is gepubliseer as 'n aandeel van die Bybelgenootskap aan die taaljaar en is oor die algemeen goed ontvang, alhoewel die kritiek nie uitgebly het nie. Die aard van 'n ine $600=1 \% 0$ dinamiese vertaling is deur min mense begryp. By baie was die die dim misn gedagte nog vasgewortel dat Bybeltaal 'n ander taal moes wees as die whacturpe eietydse gebruikstaal. Van letterkundiges het hulleself hoorbaar gemaak in geskrif en die ondigterlike taal betreur, sowel as die wegvertaal van beelde. Ook hier was die probleem dat 'n dinamiese vertaling nie begryp is nie en dat die voorrang wat aan betekenis gegee word, nie aanvaar is nie. Telkens moes 'n mens die vraag hoor: Waarom het julle dit of dat verander? en moes ' $n$ mens opnuut verduidelik dat hier nie van verandering sprake is nie maar van 'n nuwe vertaling. Dit was trouens nie die 1933-vertaling wat hersien is nie, maar 'n totaal nuwe vertaling wat gemaak is. Die deurslag is uiteindelik gegee deur die lesers. Toe die Nuwe Testament en Psalms in 1979 verskyn het, is hy wyd aanvaar en gebruik ten spyte daarvan dat die Algemene Sinode van die NG Kerk nog nie uitvoering kon gee aan ' $n$ kerkordelike bepaling wat vasgestel het dat alleen vertalings wat deur die Sinode goedgekeur is, van die kansel af gebruik kon word nie. Na afhandeling van die Nuwe Testament en Psalms, is die eindredaksie opnuut saamgestel en is oorgegaan tot 'n nuwe werkmetode. Tot op hierdie stadium was daar nie minder nie as ses verskillende stadia waardeur die vertaling gegaan het 
voordat dit gefinaliseer is. Dit is nou verminder tot vier waarin die konsepvertaling eers deur 'n klein komitee tesame met die vertalers self hersien is voordat dit aan die eindredaksie voorgelê is, waarna dit nog deur drie hersieningsfases gegaan het voordat dit gereed was vir finale hersiening. Hierdie werkwyse het sake baie bespoedig. Teen hierdie tyd was daar ook al 'n redelike ooreenstemming onder die vertalers oor die wyse van weergawe. Die nuwe werkmetode het harde werk beteken vir die lede van die komitee (Van Zyl en ek self) wat vir die eerste hersiening verantwoordelik was, maar ná so 'n eerste hersiening kon die hersiening in die sittings van die eindredaksie betreklik vlot verloop. Op 24 November 1982 was alles gereed vir die laaste fase, die finale hersiening. Die gepubliseerde Nuwe Testament en Psalms is in die loop van 1983 weer hersien. Dit tesame met die hersiening van die teks van die res van die $\mathrm{Ou}$ Testament is finaal afgesluit op 21 Julie 1983, die laaste sittingsdag van die huidige vertalingsprojek. Twee weke later was ook die aantekeninge gereed. Al wat oorgebly het, was die proefleeswerk, en terwyl die lede van die kommissie wat daarvoor aangewys is elkeen sy deel gedoen het, het die swaarste las in hierdie opsig weer eens geval op die sekretaris, prof AH van Zyl.

Hierdie onvolledige oorsig kan afgesluit word met enkele aantekeninge oor spesifieke sake. Wat eiename betref, is reeds in die begin van die sestigerjare ondersoek ingestel deur prof PFD Weiss vir die Ou Testament en prof Jac J Muller vir die Nuwe Testament. Prof Weiss het ' $n$ transkripsiesisteem bepleit wat die uitspraak van name nader sou bring aan die Hebreeuse vorm. Dit het o a ingesluit die herinvoering van die ch en die gebruik van dubbelvokale ee, oe, ens. Prof Muller het voorgestel dat name in die Nuwe Testament nie gelykgeskakel moes word met soortgelykes in die Ou Testemant nie, dat th met $t$ weergegee word en dat deurgaans $k$ geskryf word in plaas van $c$. In albei gevalle is uitgegaan van die standpunt dat ' $n$ bepaalde aantal name vanweë bekendheid hulle tradisionele vorm sou behou. Later het ek self die opdrag ontvang om 'n lys eiename vir die Ou Testement op te stel, en 'n soortgelyke opdrag vir die Nuwe Testament is aan prof SJ Botha gegee. Die lyste deur ons opgestel, is deur die vertalerskommissie behandel op sy vergadering van 7 Junie 1971. 'n Vroeëre besluit om sekere name op die tradisionele wyse te transkribeer, is gehandhaaf. Indringende bespreking is gevoer, $o$ a oor die behoud al dan nie van die $h$ in name soos Thomas en Mattheus. Die algemene neiging was dat konserwatief opgetree 
sou word en dat aangesluit sou word by die Afrikaanse speltradisie van eiename. Verder is besluit dat deeltekens en aksente slegs gebruik sou word waar dit absoluut noodsaaklik is en dat name wat in die Ou en sowel as die Nuwe Testament voorkom, eenders weergegee sou word deur wedersydse aanpassing. Die Ou-Testamentiese groep het die beginsels wat ek in my memorandum uiteengesit het, aanvaar, maar besluit dat telkens in die teksverband bepaal sou word of die weergawe aangepas moes word. Hierdie beginsels het daarop neergekom dat een Hebreeuse letter telkens met een Afrikaanse letter weergegee sou word, dat waar van toepassing medeklinkers verdubbel sou word, behalwe in die geval van die $\mathbf{j}$, dat deurgaans van g gebruik gemaak sou word en nie van ch nie. Sowel wat die Ou en die Nuwe Testament betref, is in hierdie memoranda baie sterk aangesluit by 'n gepubliseerde lys van die Nederlandse Bybelgenootskap. Intussen is in 1971 in Stuttgart, Duitsland, die Ökumenisches Verzeichnis der Biblischen Eigennamen nach der Loccumer Richtlinien gepubliseer, en op 3 Augustus 1976 het ds $G$ van der Merwe, hoofsekretaris van die Bybelgenootskap, versoek dat ons lyste weer hersien word aan die hand van hierdie Richtlinien. Dit is gedoen en nuwe lyste is opgestel. Die vertalers het die lyste behandel in hulle vergadering van 6 Oktober 1976 en die uitgangspunt aanvaar sonder om hulle absoluut daaraan te bind. Soos die vertaalwerk gevorder het, is in hoofsaak aan die voorskrifte van hierdie lyste gehou, maar tog het die name uiteindelik in 1982 en 1983 baie tyd in beslag geneem, veral wat betref aanpassings waar binne die Ou Testament en ook in Ou sowel as Nuwe Testament verskillende name vir dieselfde persoon gebruik word. Die reël is mettertyd aanvaar dat met bepaalde uitsonderings dieselfde persoon telkens met dieselfde naam aangedui sou word. Aan die een kant is ten opsigte van eiename in die Bybel in hierdie vertaling sterk afgewyk van ' $n$ gevestigde tradisie en is die transkripsie binne die beperkte moontlikhede meer in ooreenstemming met die oorspronklike uitspraak. Aan die ander kant is wat die meer bekende name betref die tradisie eerbiedig. Ten opsigte van geografiese name is dikwels van die tradisie afgewyk ten opsigte van die samestelling. 'n Gevestigde Afrikaanse tradisie het dit noodsaaklik gemaak dat afgesien word van vorme soos "berg Sinai", "spruit van Egipte", "dal van Agor" ens. en oorgegaan tot die samestellings Sinaiberg, Egiptespruit, ens. Heelwat meer geografiese name is ook in vertaling weergegee, bv. Spooklaagte - Jos. 15:8; Jakkalsfontein - Neh. 2:13; Moorddal - Jer. 
7:32; Vakmansdal - 1 Kron. 4:14; Ribbebeensdeel - 2 Sam. 2:16 ens.

Ook wat betref mate het die vertalers hulle nie in 'n vaste sisteem laat bind nie. Metrisering is aanvaar op die grondslag van 45 sentimeter vir ' $n$ el, 22 liter vir 'n efa, 11,4 gram vir 'n sikkel in die $\mathrm{Ou}$ Testament, 14 gram vir'n sikkel in die Nuwe Testament en 3,5 vir'n dragma. Maar die vertalers het deurgaans probeer om 'n natuurlike weergawe te gee met voorrang aan betekenis. Die konsekwente weergawe van die koninklike el met $521 / 2$ sentimeter by die heiligdom het bv. gelei tot twee en selfs drie desimale op plekke, en daarom is uiteindelik besluit op 'n ekwivalent van 50 sentimeter, vir 'n koninklike el, wat die onderlinge verhoudinge van die mate van bv. die tempel duideliker laat uitkom het.

'n Sterk afwyking van die tradisie is ook die weergawe van die godsnaam "Jahwe" met Here liewer as met HERE. Dié weergawe het sy eie verloop gehad. Aanvanklik is besluit om DIE HERE te skrywe omdat die geheel 'n weergawe van "Jahwe" is. Mettertyd het die vraag egter ontstaan waarom juis in hierdie een geval ortografies vir die leser aangedui moes word wat in die oorspronklike teks staan. Vir die Afrikaanse leser wat oplettend is, kon die skryfwyses, soms met hoofletters, ander kere sonder hoofletters, slegs verwarrend wees, en eintlik het dit net betekenis gehad vir diegene wat Hebreeus geken het. Daarom is teruggegaan na die tradisie van die Nuwe Testament toe wat op sy beurt aangesluit het by die tradisie van die Griekse vertaling van die Ou Testament wat Jahwe gewoon met kurios weergegee het.

'n Besondere probleem was die voorkoms van die godsnaam "Adonai Jahwe" wat in die 1933-vertaling weergegee is met Here HERE. Dit word nou meesal weergegee met "die Here God" of "die Here my God".

Aan die inhoud en aard van die vertaling kan uiteraard in so 'n kort oorsig nie aandag gegee word nie. Al wat ek op hierdie stadium wil beklemtoon, is dat dit inderdaad ' $n$ nuwe vertaling is wat die insigte van die vertalers in hierdie tyd en omstandighede weerspieël. Hoe radikaal die verskil van die 1933-vertaling soms is, blyk uit 'n vergelyking van Ps. 16:3 in die twee weergawes: "Maar aangaande die heiliges wat op die aarde is, sê ek: Hulle is die heerlikes in wie al my behae is" (1933), teenoor "Die afgode in die land, so aantreklik vir baie - met hulle wil ek niks te doen hê nie" (1983), en Jer. 31:26: "(Hierop het ek wakker geword en opgekyk, en my slaap was vir my soet)" (1933) teenoor "Dit is waarom Ek ingryp: 
Ek het alles gesien, Ek sal nie terugkom op my besluit nie" (1983). Oor die algemeen egter sal die verskil nie soseer in betekenisweergawe lê nie maar in die wyse waarop dit gedoen is. Oor die verdienste of onverdienste van die 1983-vertaling sal mettertyd uitsprake gemaak word deur diegene wat dit sal hanteer, sommige met insig, ander daarsonder. Wat die vertalers self betref, hulle het in hierdie dertien jaar kleiner geword, meer bewus van onvermoë en gebreke.

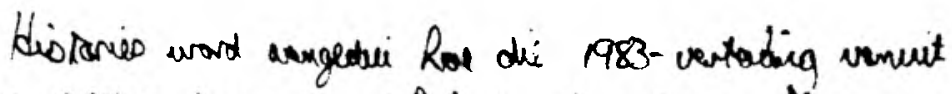

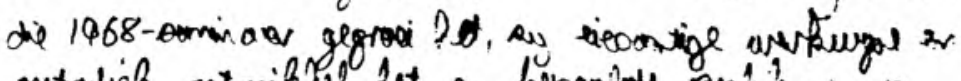

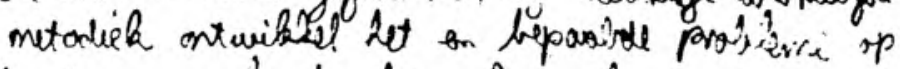
ir eie uxpe Louter 2t. Die rol ver die outeur in

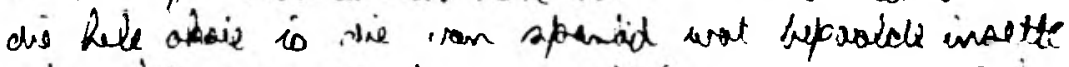

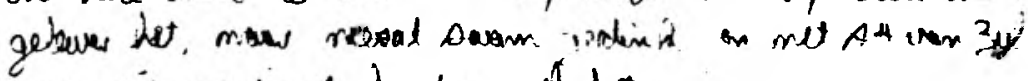

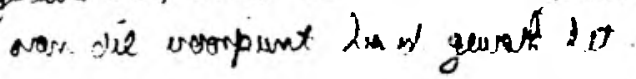

91 